\title{
Accuracy of Frozen-Section Diagnosis of Brain Tumors: An 11-Year Experience from a Tertiary Care Center
}

\author{
Fatima Nouri OBEIDAT ${ }^{1}$, Heyam Adnan AWAD ${ }^{1}$, Ahmad Talal MANSOUR ${ }^{1}$, Manar Hussein HAJEER ${ }^{1}$, \\ Mohammad Asem AL-JALABI ${ }^{1}$, Loay Emad ABUDALU²
}

${ }^{1}$ The University of Jordan, Department of Pathology \& Microbiology and Forensic Medicine, Amman, Jordan
${ }^{2}$ King Hussein Cancer Center, Department of Pathology and Laboratory Medicine, Amman, Jordan

Corresponding author: Fatima OBEIDAT fatima.obeidat1971@outlook.com; Fatima.obeidat@ju.edu.jo

\section{ABSTRACT}

AIM: To analyze the frozen section (FS) diagnostic accuracy in correlation with the final diagnosis of brain tumors.

MATERIAL and METHODS: This retrospective study comprised all brain tumor cases with FS diagnosis and permanent section diagnosis in Jordan University Hospital from July 1, 2007 to December 31, 2017. Data were obtained by reviewing slides and reports from the histopathology archives. Statistical Package for the Social Science (SPSS) software v20 was used for analysis.

RESULTS: A total of 179 cases with frozen section and permanent section diagnoses were analyzed. Eighty-four (47\%) patients were males and 95 (53\%) females. The ages ranged from 1 to 85 years. Diagnostic accuracy of FS was $88.8 \%$. Discrepancy was noted in 20 cases. Of the discrepancies, misclassification of tumor type was the most common category (12 cases, $60 \%)$, followed by grading mismatch (7 cases, 35\%) and misdiagnosis of tumor versus non-tumor conditions (1 case, $5 \%$ ). Patient age and gender were not significantly associated with the discrepancy between FS and final diagnosis.

CONCLUSION: Our results were comparable to international reports. However, more emphasis on diagnostic cytology in intraoperative consultation is required as an effective adjunct to frozen section to overcome limitations.

KEYWORDS: Frozen section, Accuracy, Central nervous system, Tumors

ABBREVIATIONS: FS: Frozen section, CNS: Central nervous system, SPSS: Statistical Package for the Social Science

\section{INTRODUCTION}

I ntraoperative consultation for intracranial lesions is widely used to assist neurosurgical treatment decisions (14). Primary diagnosis, assessment of margins of excision, and nodal status assessment are the major indications for intraoperative consultations on several types of tissues (18). From a neurosurgical viewpoint, intraoperative consultation on neurosurgical specimens is a valuable guide for the best intra- or postoperative patient management (28). The rapid technique of frozen section (FS) is a reliable investigation that has par- amount importance to the surgeon (14). FS of a suspected central nervous system (CNS) neoplasm is chiefly performed to assess the adequacy of the submitted tissue in the setting of stereotactic biopsies (10), and several ancillary studies can be performed on the submitted tissue before routine processing $(10,12,17,25,26)$. In addition, tumors such as astrocytomas and oligodendrogliomas can be intraoperatively diagnosed with great success using smear cytology (24), and the diagnostic yield for most tumor types can be substantially increased when crush smears and FSs are used simultaneously (6). The accuracy of FS diagnosis of CNS lesions has
Fatima Nouri OBEIDAT (D): 0000-0002-8836-919X Heyam Adnan AWAD (1) : 0000-0003-3050-136X Ahmad Talal MANSOUR (1) : 0000-0003-3867-4476
Manar Hussein HAJEER

Mohammad Asem AL-JALABI

Loay Emad ABUDALU
(D) : 0000-0002-5591-6900

: : 0000-0002-5843-1722

(D) : 0000-0002-8935-4133 
been debated worldwide, and multiple factors should be considered to make accurate diagnoses (28). Moreover, FS can be sometimes harmful to the patient. Good communication with the surgeon is required to avoid such cases (28). Because improvements are continuously required in the pathology practice, the correlation between FS and permanent section diagnoses needs to be periodically monitored (20). Assessment of discordance rates between FS diagnoses and final diagnoses is required to address the causes of FS errors and the impact of such errors on the patients (16). Several studies have been conducted worldwide to assess the diagnostic accuracy of FS in general, and the overall accuracy of FS diagnosis has been extensively studied. This accuracy rate falls within the range of 92 to $97.98 \%$ as shown in several reports $(1,7,8,11,13,16,18,27)$. Regarding neurosurgical specimens, continuous evaluation of FS diagnostic accuracy is required to overcome the errors, limitations, and pitfalls that can be faced in the diagnosis of CNS lesions. The diagnostic process can be greatly affected by the technical errors in FS. Freezing artifacts due to the ice crystals introduced into the examined tissue, crushing artifacts, and overstretching artifacts seen in cytology preparations are common technical errors faced in the intraoperative consultations performed on neurosurgical specimens. In addition, cautery and crushing artifacts, which may be caused by the surgeon, can affect the tissue architecture significantly. The pathologist should be aware of all these factors when performing intraoperative consultations. Common challenges faced include differentiating lymphomas from high-grade gliomas, difficulties in diagnosing spindle cell lesions, diagnosis of highly vascular tumors and differentiating metastatic carcinoma from other types of tumors (21). Diagnostic pitfalls of intraoperative consultation were systematically addressed in many studies, and the diagnostic accuracy of intraoperative consultation of CNS lesions was reported to be in the range of 85 to $90 \%$ in most of these studies $(10,19,22-24)$. This is the first study carried out in Jordan on FS diagnostic accuracy in the CNS. Comparing our results with other reports from around the world, including our region, adds to the knowledge on FS diagnostic accuracy in the CNS and paves the way for further improvements to overcome possible limitations.

\section{MATERIAL and METHODS}

This retrospective study comprised all brain tumor cases with FS and permanent-section diagnoses from July 1, 2007 to December 31, 2017 at Jordan University Hospital in Amman, Jordan. After the institutional review board approval, the data were gathered from the computer system, and the slides were retrieved from the archives of the Histopathology Department at Jordan University Hospital. Each case was intraoperatively diagnosed by 1 of 8 staff pathologists, as was the final diagnosis of each case. All cases were blindly reviewed by an experienced neuropathologist and a general pathologist. The data of the cases comprised age and gender, and comparison between FS diagnosis and final diagnosis was done (3). SPSS v20 was used for data analysis. Pearson's chi-squared test was used for statistical analysis, and $\mathrm{P}<0.05$ was considered significant.

\section{RESULTS}

Frozen sections were used for 181 cases during the study period. One case was not representative, and another case was deferred to the permanent section. These two cases were excluded from the study. Further analysis of the 179 cases revealed that there were $84(47 \%)$ male and $95(53 \%)$ female patients. The ages of the patients ranged from 1 to 85 years (mean age $44.72 \pm 19.93$ years). Twelve patients $(7 \%)$ were aged $\leq 9$ years, $12(7 \%)$ were aged $10-19$ years, $42(23 \%)$ were aged $20-39$ years, $65(36 \%)$ were aged $40-59$ years, and $48(27 \%)$ were aged $\geq 60$ years. Of the 179 cases, astrocytic tumors represented the largest group of diagnostic categories (71 cases, 39.8\%). Meningioma (42 cases, $24 \%$ ) and metastasis ( 13 cases, $7 \%$ ) were the second and third most common diagnostic categories, respectively (Table I). Comparison of the FS diagnoses and the final diagnoses revealed that 20 cases (11.2\%) were discordant. Further analysis of the discrepant cases revealed that there were $10(50 \%)$ male and $10(50 \%)$ female patients, with a male-to-female ratio of 1:1. The mean age in the discrepant diagnosis group was $39.20 \pm$ 24.59 years with a minimum of 1 and a maximum of 85 years old. The mean age and male-to-female ratio didnot differ significantly between the discrepant and nondiscrepant groups (Table II). After stratifying the patients into 5 main age groups, the statistical analysis revealed that age was not significantly associated with discrepancy (Table III). Further analysis of discrepant cases revealed that the discrepancies were most commonly found in astrocytic tumor cases (10 cases, 50\%). The second and third largest groups of discrepancies were mesenchymal tumors (10\%, two cases of anaplastic heman-

Table I: General Categories of Studied Cases

\begin{tabular}{lc}
\hline Category & $\mathbf{n}(\%)$ \\
\hline Astrocytic tumor & $71(39.8)$ \\
\hline Oligodendroglial tumor & $6(3.4)$ \\
\hline Ependymal tumor & $4(2.2)$ \\
\hline Meningioma & $42(23.5)$ \\
\hline Embryonal tumor & $7(3.9)$ \\
\hline Tumor of peripheral nerve sheath & $11(6.1)$ \\
\hline Hemangioblastoma & $1(0.5)$ \\
\hline Lymphoma & $3(1.7)$ \\
\hline Mesenchymal tumor & $7(3.9)$ \\
\hline Germ cell tumor & $1(0.5)$ \\
\hline Tumor of choroid plexus & $2(1.1)$ \\
\hline Neurocytoma & $1(0.5)$ \\
\hline Pituitary tumor & $7(3.9)$ \\
\hline Metastatic tumor & $13(7.3)$ \\
\hline Nonneoplastic lesion & $3(1.7)$ \\
\hline Total & $179(100)$ \\
\hline
\end{tabular}


Obeidat FN. et al: Frozen-Section Diagnosis of Brain Tumors

Table II: Demographic Features of Discrepant Age (years) and Nondiscrepant Cases

\begin{tabular}{|c|c|c|c|c|c|c|}
\hline Category & $\mathbf{n}$ & M/F & $\mathbf{p}$ & $\begin{array}{c}\text { Mean age } \\
\text { (years) }\end{array}$ & SD & $\mathbf{p}$ \\
\hline Discrepant & 20 & $10 / 10$ & \multirow{3}{*}{0.477} & 39.20 & 24.59 & \multirow{3}{*}{0.189} \\
\hline Nondiscrepant & 159 & $74 / 85$ & & 45.42 & 19.24 & \\
\hline Total & 179 & $84 / 95$ & & 44.72 & 19.93 & \\
\hline
\end{tabular}

F: Female, M: Male, SD: Standart deviation.

Table III: Age Characteristics of Discrepant and Nondiscrepant Cases

\begin{tabular}{lccc}
\hline Criteria & $\begin{array}{c}\text { Discrepant } \\
\mathbf{n}(\%)\end{array}$ & $\begin{array}{c}\text { Nondiscrepant } \\
\mathbf{n}(\%)\end{array}$ & $\mathbf{p}$ \\
\hline Age (years) & & \\
\hline$\leq 9$ & $3(25.0)$ & $9(75.0)$ & \\
\hline $10-19$ & $2(16.7)$ & $10(83.3)$ & \\
\hline $20-39$ & $5(11.9)$ & $37(88.1)$ & \\
\hline $40-59$ & $3(4.6)$ & $62(95.4)$ & \\
\hline$\geq 60$ & $7(14.6)$ & $41(85.4)$ & \\
\hline Total & $20(11.2)$ & $159(88.8)$ & \\
\hline
\end{tabular}

giopericytoma) and ependymal tumors (10\%, one case of grade II and another one of grade III) (Table IV). Our results revealed that there were 3 major categories of discrepancies. Misclassification of tumor type was the most common category (12 cases, $60 \%$ ), followed by grading mismatch ( 7 cases, $35 \%)$ and misdiagnosis of tumor versus non-tumor conditions (1 case, 5\%) (Table IV). Of the tumor type misclassification categories, the most common pitfall was in the diagnosis of glioblastoma, of which 3 cases were misdiagnosed as medulloblastoma, small round blue cell tumor, and metastasis on FS evaluation. In the grading mismatch category, there were 4 cases diagnosed intraoperatively as having high-grade glioma (1 astrocytoma grade II, 1 pleomorphic xanthoastrocytoma, 1 pilocytic astrocytoma, and 1 astroblastoma), and 3 cases diagnosed intraoperatively as low-grade glioma (1 glioblastoma and 2 anaplastic astrocytomas). One case that was misdiagnosed as gliosis on FS examination was finally diagnosed as anaplastic oligodendroglioma.

\section{DISCUSSION}

This was the first study performed in our country that aimed to systematically address the possible diagnostic pitfalls in intraoperative consultation of CNS lesions. Despite the usefulness of rapid intraoperative diagnosis for neurosurgical management, the pathologist may be faced with multiple difficulties and resulting pitfalls, which requires periodic monitoring of FS-permanent section correlation data (20). The diagnostic accuracy of intraoperative consultation in our study was $88.8 \%$. Interestingly, this was slightly higher than the $87.6 \%$ reported in a large French study of 1,315 cases (22). In addition, the figure was close to that of a recent large study from Thailand, which was carried out in 774 cases and showed an accuracy rate of $89 \%$ (9). Another study from Karachi, Pakistan also reported a similar result (88.9\%) (29). In general, the accuracy in our study was comparable to the range reported by others. However, our ratio was much lower than that of a study from Iran (99.5\%) (15). This might be explained by their consideration of partially concordant cases. Because not all the diagnoses in the present study were given by the same pathologist, the results might be influenced by inter-observer variability. However, analysis of discrepant cases addressed common problematic categories. Tumor type misclassification was the most common pitfall, especially the misdiagnosis of glioblastoma. This was also reported by others, especially the misinterpretation of high-grade gliomas as metastatic carcinomas or other non-glial tumor types $(9,17,19,23,24)$. Misdiagnosing non-glial neoplasms as gliomas was also reported as a common discrepancy (29). Such pitfalls in diagnosing glial versus non-glial neoplasms can be minimized by using cytologic smears and FS together since cytologic smears effectively demonstrate the cellular features of glial neoplasms and help differentiate them from those of epithelial origin (24). These findings necessitate improvements in applying and interpreting cytology slides as an effective adjunct to FS in intraoperative consultation on neurosurgical specimens. Another common difficulty regarding the diagnosis of glioblastoma is the diagnosis of small cell variant glioblastoma $(2,19,29)$. One example of this tumor type was diagnosed intraoperatively at our department as small round blue cell tumor. Tumor type misclassification of spindle cell lesions, especially meningiomas, is a common misclassification pitfall reported by others $(2,15,19)$. Morphological variations, such as the lack of typical features of meningioma represented by whorls and psammoma bodies may lead to misdiagnosing meningioma as a different spindle cell tumor type $(4,5)$. Additionally, features that may be occasionally shared by other spindle cell tumors, such as schwannoma, are also important factors for misdiagnosing such lesions as meningiomas. For example, the classic biphasic pattern of schwannoma may not be evident in the tissue examined (19). However, our study showed a high accuracy rate in diagnosing meningioma, which is comparable to that reported by Roessler et al. (23). This might be related to the good communication with surgeons and the good clinicoradiological correlation. Another pitfall in the category of misclassification, which may have serious effects on clinical management, is the misdiagnosis of lymphoma, especially if it is misdiagnosed as a tumor type for which 
Table IV: Categories and Details of Discrepant Cases

\begin{tabular}{|c|c|c|c|}
\hline Category & FS diagnosis & Final diagnosis & No. of cases \\
\hline \multirow{12}{*}{ Misclassification } & Small round blue cell tumor & Glioblastoma & 1 \\
\hline & Metastasis & Glioblastoma & 1 \\
\hline & Medulloblastoma & Glioblastoma & 1 \\
\hline & Meningioma & Anaplastic hemangiopericytoma & 1 \\
\hline & Medulloblastoma & Ependymoma & 1 \\
\hline & High grade glioma & Medulloblastoma & 1 \\
\hline & Ependymoma & Neurocytoma & 1 \\
\hline & Spindle cell lesion & Anaplastic ependymoma & 1 \\
\hline & Spindle cell lesion & Hemangioblastoma & 1 \\
\hline & Primitive neuroectodermal tumor & Anaplastic hemangiopericytoma & 1 \\
\hline & Metastasis & Diffuse large B cell lymphoma & 1 \\
\hline & Glioblastoma & Metastatic carcinoma & 1 \\
\hline \multirow{7}{*}{ Grading mismatch } & Low grade glioma & Anaplastic astrocytoma & 1 \\
\hline & Low grade glioma & Anaplastic astrocytoma & 1 \\
\hline & Low grade glioma & Glioblastoma & 1 \\
\hline & High grade glioma & Astrocytoma grade II & 1 \\
\hline & High grade glioma & Pleomorphic xanthoastrocytoma & 1 \\
\hline & High grade glioma & Pilocytic astrocytoma & 1 \\
\hline & High grade glioma & Astroblastoma & 1 \\
\hline Tumor versus non-tumor & Gliosis & Anaplastic oligodendroglioma & 1 \\
\hline
\end{tabular}

surgery is the primary treatment. Careful clinicoradiological correlation and good communication with the neurosurgeon can help overcome this pitfall. Additionally, considering the possibility of adjacent gliosis in a case of lymphoma can help to avoid misinterpreting such lesions as gliomas (20). At our department, there was 1 case of diffuse large B cell lymphoma that was misdiagnosed as metastatic carcinoma.

The second most common category of discrepancy in our study was grading mismatch, representing $35 \%$ of the discrepancies (7 cases). Deviation of tumor grading was also reported as a relatively common pitfall by several studies from around the world, including our region $(2,9)$. In a recent study from Oman, grading mismatch, and especially undergrading, was the most common discrepancy (2). According to our findings, overgrading represented 4 of the 7 cases in this category. Assessment of pleomorphism and cellularity can be significantly affected by the artifacts of FS, which make other features, such as microvascular proliferation and necrosis, more reliable for accurate diagnosis. It is also important to note that of the 4 cases of overgrading, 1 case was finally diagnosed as pilocytic astrocytoma and another one as pleomorphic xanthoastrocytoma. These findings highlight the importance of clinicaland radiological correlation for avoiding such pitfalls. The disagreement in higher and lower grade lesions also included 3 high-grade tumor cases (2 anaplastic astrocytomas and 1 glioblastoma), which were intraoperatively diagnosed as low-grade glioma. In these circumstances, especially when the size of the sample received intraoperatively is small, a careful search for high-grade features is mandatory to avoid such undergrading. Moreover, the grading may vary between different areas in the same tumor, and it can be affected by sampling errors (17). The third category of discrepancies in our study was in distinguishing between reactive and neoplastic lesions. There was one case of oligodendroglioma which was reported intraoperatively as gliosis. Sampling and pathologist's experience play an important role in such cases.

\section{- CONCLUSION}

Our results were comparable to international reports. However, pitfalls are present, and more effort is needed with more emphasis on utilizing diagnostic cytology in intraoperative consultation as an adjunct to FS. In addition, good clinicoradiological correlation must be maintained in all conditions. 


\section{REFERENCES}

1. Abbasi F, Yekta Z, Aryan A: Accuracy of frozen sections. Iran J Pathol 7:3-8, 2012

2. Al-Ajmi R, Al-Kindi $\mathrm{H}$, George $\mathrm{M}$, Thomas $\mathrm{K}$ : Correlation of intraoperative frozen section report and histopathological diagnosis of central nervous system tumors-a six-year retrospective study. Oman Med J 31:414, 2016

3. Bosman F, Jaffe E, Lakhani S, Ohgaki H: WHO classification of tumors of central nervous system. Lyon: IARC, 2013:10-12

4. Burger PC: Use of cytological preparations in the frozen section diagnosis of central nervous system neoplasia. Am J Surg Pathol 9:344-354, 1985

5. Burger PC, Vogel SF: Frozen section interpretation in surgical neuropathology, I: Intracranial lesions. Am J Surg Pathol 1: 323-347, 1977

6. Chand P, Amit S, Gupta R, Agarwal A: Errors, limitations, and pitfalls in the diagnosis of central and peripheral nervous system lesions in intraoperative cytology and frozen sections. J Cytol 33:93, 2016

7. Chandramouleeswari K, Yogambal M, Arunalatha P, Bose $\mathrm{JC}$, Rajendran A: Frozen and paraffin sections-comparative study highlighting the concordance and discordance rates in a tertiary care centre. IOSR-JDMS 12:26-30, 2013

8. Chang JL, Tseng HH, Sheu LF, Lee WH, Tu YC: Diagnostic accuracy of frozen sections in surgical pathology-a retrospective analysis of 1084 frozen sections. J Med Sci 13:133-142, 1992

9. Cheunsuchon P, Punyashthira A, Tanboon J, Sangruchi T: Accuracy of intraoperative consultation of central nervous system lesions in Siriraj hospital. SMJ 66:113-119, 2017

10. Di Stefano D, Scucchi LF, Cosentino L, Bosman C, Vecchione A: Intraoperative diagnosis of nervous system lesions. Acta Cytol 42:346-356, 1998

11. Farah-Klibi F, Neji O, Ferjaoui M, Zaouche A, Koubaa A, Sfar $\mathrm{R}$, et al: Accuracy of frozen section diagnosis: An analysis of 1695 consecutive cases. Tunis Med 86:693-697, 2008

12. Firlik KS, Martinez AJ, Lunsford LD: Use of cytological preparations for the intraoperative diagnosis of stereotactically obtained brain biopsies: A 19-year experience and survey of neuropathologists. J Neurosurg 91:454-458, 1999

13. Howanitz PJ, Hoffman GG, Zarbo RJ: The accuracy of frozensection diagnoses in 34 hospitals. Arch Pathol Lab Med 114: 355-359, 1990

14. Jaafar $\mathrm{H}$ : Intra-operative frozen section consultation: Concepts, applications and limitations. Malays J Med Sci 13: 4, 2006

15. Khoddami M, Akbarzadeh A, Mordai A, Bidari-Zerehpoush F, Alipour H, Samadzadeh S, Alipour B: Diagnostic accuracy of frozen section of central nervous system lesions: A 10-year study. Iran J Child Neurol 9:25, 2015
16. Mahe E, Ara S, Bishara M, Kurian A, Tauqir S, Ursani N, Vasudev P, Aziz T, Ross C, Lytwyn A: Intraoperative pathology consultation: Error, cause and impact. Can J Surg 56:E13, 2013

17. Mitra S, Kumar M, Sharma V, Mukhopadhyay D: Squash preparation: A reliable diagnostic tool in the intraoperative diagnosis of central nervous system tumors. J Cytol 27:81, 2010

18. Patil P, Shukla S, Bhake A, Hiwale K: Accuracy of frozen section analysis in correlation with surgical pathology diagnosis. Int $\mathrm{J}$ Res Med Sci 3:399-404, 2015

19. Plesec TP, Prayson RA: Frozen section discrepancy in the evaluation of central nervous system tumors. Arch Pathol Lab Med 131:1532-1540, 2007

20. Raab SS, Tworek JA, Souers R, Zarbo RJ: The value of monitoring frozen section-permanent section correlation data over time. Arch Pathol Lab Med 130:337-342, 2006

21. Rao S, Rajkumar A, Ehtesham MD, Duvuru P: Challenges in neurosurgical intraoperative consultation. Neurol India 57: 464, 2009

22. Regragui A, Amarti Riffi A, Maher M, El Khamlichi A, Saidi A: Accuracy of intraoperative diagnosis in central nervous system tumors: report of 1315 cases. Neurochirurgie 49:6772, 2003

23. Roessler K, Dietrich W, Kitz K: High diagnostic accuracy of cytologic smears of central nervous system tumors: A 15-year experience based on 4,172 patients. Acta Cytol 46:667-674, 2002

24. Savargaonkar P, Farmer PM: Utility of intra-operative consultations for the diagnosis of central nervous system lesions. Ann Clin Lab Sci 31:133-139, 2001

25. Sharma S, Deb P: Intraoperative neurocytology of primary central nervous system neoplasia: A simplified and practical diagnostic approach. J Cytol 28:147, 2011

26. Shioyama T, Muragaki $\mathrm{Y}$, Maruyama T, Komori T, Iseki H: Intraoperative flow cytometry analysis of glioma tissue for rapid determination of tumor presence and its histopathological grade. J Neurosurg 118:1232-1238, 2013

27. Shrestha S, Lee MC, Dhakal H, Pun CB, Pradhan M, Shrestha $\mathrm{S}$, Basyal R, Pathak T: Comparative study of frozen section diagnoses with histopathology. PMJN 3:1-5, 2009

28. Somerset HL, Kleinschmidt-DeMasters BK: Approach to the intraoperative consultation for neurosurgical specimens. Adv Anat Pathol 18:446-449, 2011

29. Ud Din N, Memon A, Idress R, Ahmad Z, Hasan S: Central nervous system lesions: Correlation of intraoperative and final diagnoses, six year experience at a referral centre in a developing country, Pakistan. Asian Pac J Cancer Prev 12: 1435-1437, 2011 